\title{
Effect of Outward Bound on College Students' Social Adaptability
}

\author{
Yuan Wen, Dupin Xie \\ Nanchang Institute of Science \& Technology, Nanchang City, Jiangxi \\ Province, 330108, China
}

\begin{abstract}
Outward bound has unique effects and advantages in improving the psychological quality of bearing pressure and facing frustration, and social adaptability of interpersonal communication, teamwork, exploration and innovation. Therefore, the introduction of outward bound into the curriculum system of college sports health education is not only the expansion of the social function of outward bound in school sports, but also the active exploration and innovation of college physical education in pursuit of students' physical and mental health and improvement of their social adaptability. In this paper, based on the authors' learning and practical experience, we first analyzed the theory and its function of outward bound, and then investigated the effect of outward bound on college students' social adaptability.

Keywords: physical education; outward bound; college students; social adaptability; effect
\end{abstract}

\section{Introduction}

Outward bound has been paid wide attention by the college educational circles due to its unique educational concept and teaching mode. Outward bound is a new way of education in modern western countries, which is guided by physical activity, focused on psychological challenges and aimed at perfecting personality[1]. The purpose of this study is to explore the impact of outward bound on the mental health and social adaptability of college students, which provides theoretical basis and practical experience for the improvement of physical education teaching reform. 


\section{Outward bound theory and its function}

Outward bound is an experiential learning method that the natural conditions and environment as well as a variety of typical facilities and projects with special design are used to conduct many kinds of targeted and challenging activities, which make the trainees master a certain survival skills, develop their minds, and cultivate their teamwork spirit. At present, outward bound has been widely recognized in enhancing team cohesion, improving social adaptability and mental health level, and strengthen the interpersonal communication. Both outward bound and physical sports are physical and mental experience activities. The characteristics of outward bound are clear and targeted, which are the combination of advocating individuality with emphasizing team, the combination of challenging the limit with mining the potential, and the combination of collective sublimation with self-education[2].

Outward bound focuses on improving the psychological quality of the participants in physical exercises, and consider the effect of psychological improvement as an important criterion for the evaluation of all the activities. The design of many items in outward bound need to tap the potential of the participants and challenge their limits, and is often completed with the help and cooperation of team members. Therefore, the participants can not only experience their own sense of accomplishment, but also have a more profound experience towards teamwork spirit and awareness[3]. Outward bound makes full use of a variety of environmental factors to create a variety of activities according to local conditions. While the original purpose of the activities is achieved, the participants can often learn some practical survival skills, and experience the harmony between human and nature in a emotion and circumstance blending atmosphere.

\section{Effect of Physical Outward Bound on College Students' Social Adaptability}

\subsection{Effect of individual items in outward bound on the social adaptability of college students}

First, the individual items in outward bound can improve the inferiority complex, enhance morale, and strive to realize breakthrough. If a person is in the highaltitude environment, his mentality will change. Then the fear and retreat are followed like the encountered frustrations in everyday life. It is inevitable for many people to want to give up in the high-altitude outward bound, which is like the situation that one lacks the confidence to persist and decides to give up when encountering difficulties. Therefore, the high-altitude items can be used to exercise students' psychological quality, in which the students can tap their own potentials, and feel the ability change of completing the task in a special state, and the value of completing individuals' challenge with the team encourage and help. Generally, the outward bound items commonly used are: high-altitude broken bridge, horizontal bar in the air, single-plank bridge, descent along the 
rope, flying fox in the air, rock climbing, Burma bridge and so on.

Taking "horizontal bar in the air" for example, in the process of experience, the higher the students climb, the greater the column shakes. When one approaches the round table, the column shakes more intensively. Some students will hold the round table and cry in the dilemma, who are reluctant to set foot on the round table or do not dare to stand up and jump towards the horizontal bar. In this case, we can set a different across lengths according to the situation of different students, which make the difficulty moderate[4]. In this manner, the students can conduct psychological challenges under their own ability, and experience the emotions such as courage, peer encouragement and persistence in this process. The teachers can give students timely and correct counseling via psychological counseling mode, encourage students to complete the challenge, learn to share after the experience, make the students self-review, self-evaluation and selfrealization, and express their feelings, which could make the students achieve self-examination, and improve their mental capacity and ability to deal with setbacks.

Second, the individual items in outward bound can cultivate interpersonal mutual trust and cooperation awareness, and enhance self-expression. In the process of outward bound, students need to trust and collaborate in order to smoothly complete the tasks proposed by teachers. Outward bound provides a special situation for them, which needs both the courage of individuals and the trust provided by the other challengers, and not only cultivates the individual's trust in others, but also exercises the individual's self-ability.

For example, the item "Trust Fall" requires that a student is asked to drop straight from a 1.5-meter-high backstroke, and other students flatten their arms to protect him from falling. The reason why the student in the game dare to do the free fall movement is that he is confident and trusts in others, namely the student believes that the team can provide him with a security barrier so that he can safely land. In the course of practice, the participant is full of fear, do not trust the companion, and do not dare to complete the item[5]. Then the participant overcomes psychological fear with encourage and help of group members, enhance the trust and understanding towards companions, and finally complete the exercise. This item increases the participant's self-confidence and psychological quality of daring to challenge himself. In the "high-profile speech" training, the students need to stand on the preset high platform, face the following people to tell their own past, present and imaginary future in a minute, which also exercises the students' language expression ability in front of the public.

\subsection{Effect of group items in outward bound on the social adaptability of college students}

First, the group items in outward bound can cultivate the dedication spirit, and improve emotional tension and anxiety. Generally, in the team training, the teachers will set up situations with different difficulty, which need teamwork to complete. However, some cases, especially the low-altitude items, mainly cultivate the students' awareness of mutual trust and close cooperation when they 
face the crisis, and improve each student's ability to help and learn from each other in a special context, and spirit and courage to cooperate to overcome the difficulties, which have a higher value for individuals and team to improve challenge ability. The common group items in outward bound are power grid, survival in the island, canned shoes, obstacle crossing, water intaking in thorns and survival wall. Some group items in outward bound should be conducted on the water or in the mountainous areas, which have very high requirements for students' physical and mental capacity. Even if they are completed on the ground, the students still need to pay out willpower, and insist on them[6].

For example, the practice method of the group item of "chain hand" is described as follows. Each group members stand in a circle. The teacher guides the students to stretch out of the right hand to hold the opposite student's hand, and then raise his left hand to hold another student's hand. It requires that the student's two hands cannot seize the same person's two hands. Under the condition of not releasing the hands, the student should think of ways to untie this "disorderly network". Finally, a large enclosed circle forms in the manner of hand in hand. This item can test students' ability to insist, overcome the anxiety and difficulty, and ultimately complete the item in complex situations. This item also allows students to experience the truth that "victory is often a further perseverance" which can cultivate the students' strong will of overcoming the difficulties, and enhance their mental endurance.

Second, the group items in outward bound can cultivate team spirit, and feel the care the team gives. The future society have not only competition but also cooperation. Cooperation and competition are indispensable wings for the development of each person[7]. Many work and tasks must be completed via team division and cooperation. However, many people including college students lack the spirit of teamwork. Teamwork spirit has been fully reflected in the ground items. Compared with low-altitude items, the ground items are without the fear of high altitude, and mainly adopt approaches of restrictions on certain sensory organs (for example, muffle the eyes, not allow to speak, cannot use hand gestures). Such activities, including blind square, mine array, hand in hand knot, digital delivery and trust travel, have a higher value for exercising team. The significance of "unity is strength" can be strongly felt.

Taking "blind square" item for example, a dozen people are required to pull a bundle of chaotic rope into a square in a specified time, and all the people should be evenly distributed in the four edge. All the students should be blindfolded in the whole process. In this case, the captain needs to communicate with everyone, elaborate his views, and listen to the others' views. Based on collective consensus, a unified view can be reached, and the task can be completed through teamwork. In such outward bound, students need to take the initiative to communicate, listen and elaborate so that they can feel their roles in the team, which is mainly used to improve the incompatible malpractice of mood loss and frustration, mental emptiness and burnout, and make them experience the team strength and warmth, as well as the critical importance of the role of one member in the whole team. 


\section{Conclusion}

Outward bound course is an emerging item of college sports, which is characterized by the improvement of psychological quality and social adaptability in experiential activities. It is in line with the demand of talent cultivation in universities to set up outward bound courses in physical education teaching. The improvement of students' psychological quality via outward bound is beyond doubt. Outward bound has obvious advantages in mining their own potential, enhance self-confidence, cultivate interpersonal relationships, and improve the ability to solve problems. Outward bound is a comprehensive activity integrating education, sports, psychology and social functions. Physical training, psychological quality and social adaptability are indispensable in outward bound, which is a useful attempt to implement quality education in an all-round way.

\section{References}

[1] LI Zhe, ZHAO Baochun. Effect of outward bound on the improvement of college students' social adaptability. Guizhou Sports Science and Technology, (04), pp.23-26, 2012.

[2] WANG Haitang. Research on outward bound courses based on college students' social adaptive ability. Zhejiang Sport Science, (01), pp.95-98, 2012.

[3] ZHANG Jiajun. Effect of outward bound sports on college students' social adaptability. Heilongjiang Science and Technology Information, (36), pp.232-234, 2011.

[4] ZHANG Jinhua, ZHANG Xugang. The promotion action of outward bound courses on cultivating college students' sports interests Journal of Nanjing Industry Polytechnic College, (03), pp.89-90, 2010.

[5] ZHU Daqin. Exploration on the effect of psychological outward bound on improvement of college students' social adaptability. Guizhou Sports Science and Technology, (03), pp.48-49, 2008.

[6] HUANG Juan, LAI Jianquan. The introduction of outward bound in cultivating college students' social adaptability. Journal of Chongqing Vocational \& Technical College, (04), pp.120-122, 2008.

[7] TONG Yanhua, QI Jundi, ZHOU WenFu. The feasibility study on the application of outward bound in college physical education teaching. Shandong Social Sciences, (09), pp.145-146, 2006. 